\title{
Clinicopathological and Corresponding Genetic Features of Colorectal Signet Ring Cell Carcinoma
}

\author{
KENSUKE TAJIRI, TOMOYA SUDOU, FUMIHIKO FUJITA, TORU HISAKA, \\ TETSUSHI KINUGASA and YOSHITO AKAGI \\ Department of Surgery, Kurume University School of Medicine, Fukuoka, Japan
}

\begin{abstract}
Europe and the United States have high morbidity rates of colorectal cancer, it being the third most common new cancer among both men and women each year. Colorectal cancer morbidity is also high in Japan. Advances in surgery, chemotherapy, and molecular targeted drugs have extended the prognosis of colorectal cancer, although the effects of these treatments remain poor in some patients. Colorectal cancer almost always presents as differentiated adenocarcinoma, although one tissue type, signet-ring cell carcinoma, occurs rarely. Overall, colorectal signet-ring cell carcinoma is very infrequent among cases of colorectal cancer, however, its prognosis is reported as being extremely poor. Several reports have addressed its clinicopathological and typical genetic characteristics, such as mutation of viral oncogene Kirsten rat sarcoma (KRAS) gene, but there have been few comprehensive investigations of its characteristics and genetic background. In this review, we examine features of colorectal signet-ring cell carcinoma by summarizing its clinical and genetic characteristics.
\end{abstract}

Every year, about 600,000 people die of cancer in Europe and the United States, and about 50,000 of these deaths (8\%) are caused by colorectal cancer (CRC) (1). In Japan there are more than 30,000 deaths annually from cancer. CRC has the second-highest morbidity rates for both men and women, and these rates have been stable recently (Cancer Registry and

This article is freely accessible online.

Correspondence to: Dr. Kensuke Tajiri, Department of Surgery, Kurume University School of Medicine, 67 Asahi-machi, Kurume, Fukuoka 830-0011, Japan. Tel: +81 942353311, Fax: +81 942340709, e-mail: tajiri_kensuke@med.kurume-u.ac.jp

Key Words: Signet ring cell carcinoma, colorectal cancer, clinicopathology, gene, review.
Statistics. Cancer Information Service, National Cancer Center, Japan; http://ganjoho.jp/en/professional/statistics /table_download.html). The mortality rate for CRC is very high, it being the third among all cancers for men and the first for women (2). Most CRCs are well-differentiated adenocarcinomas, followed in order by moderately differentiated adenocarcinomas, poorly differentiated adenocarcinomas, mucinous carcinomas, signet-ring cell carcinomas (SRCC), and squamous cell carcinomas. Of these, the prevalence of SRCC in Europe and the United States is said to be $0.6-1.1 \%$ (3-5), with reports from Japan citing even lower rates of $0.2-0.64 \%$ (6-9). For this reason, there have been relatively few reports on the clinicopathological characteristics of SRCC and on analysis of its genetic background compared to typical CRC tissue types. In this review, we describe and discuss the clinicopathological characteristics of colorectal SRCC and its underlying genetic background (Table I). We also present current treatment and therapeutic trial that is considered to be suitable for SRCC.

\section{Clinicopathologic Characteristics of Colorectal SRCC}

Age/sex difference. Of cancers with SRCC tissue type, gastric cancer is well known. SRCC in gastric cancer accounts for about $25 \%$ of gastric cancer in Europe and the United States, and is said to occur somewhat more frequently than typical adenocarcinoma in people in their early 60s, young people, and women (10). On the other hand, SRCC in the colorectum is not well known in these groups. As for the age of onset, many studies have reported a younger age of onset than that of differentiated colorectal adenocarcinoma (9, 11-14). Regarding sex difference in colorectal SRCC, a few studies found clearly higher rates among women (15, 16), as seen in gastric SRCC, while others have found no difference between men and women $(7,16)$. 
Table I. Characteristics of clinical pathology and gene background of colorectal signet ring cell carcinoma and typical colorectal carcinoma.

\begin{tabular}{lcc}
\hline Feature & SRCC & Typical CRC \\
\hline Gender & No difference & No difference \\
Age & $<60$ Years & $>60$ Years \\
Location & Not sure & Left side>right side \\
Macroscopic/microscopic type & Type 3,4 & Type 1,2 \\
Depth/invasion/recurrence & Deep/positive/high & Various/various/various \\
Prognosis & Poor & Good \\
Intercellular adhesion molecules & Decline & Stable \\
RAS/RAF mutation & High frequency, $>50 \% />30 \%$ & Low frequency, $<40 \% /<20 \%$ \\
MSI/CIMP & Stable,$<30 \% /$ same frequency $~ 50 \%$ & Stable, $<15 \% /$ low frequency, $<20 \%$ \\
LOH & High frequency, $>90 \%$ & Low frequency, $>70 \%$ \\
MMPs & Overexpression & Various \\
MicroRNA involvement & Unknown & Various
\end{tabular}

SRCC: Signet ring cell adenocarcinoma; CRC: colorectal cancer; CIMP: CpG island methylation phenotype; MSI: microsatellite instability; LOH: loss of heterozygosity; MMP: matrix metalloproteinase.

Location. Right colon cancer more frequently harbors microsatellite instability (MSI)-high, CpG island methylation phenotype (CIMP)-high and B-rapidly accelerated fibrosarcoma $(B R A F)$ mutation than left colon cancer (17). Accordingly, colorectal SRCC should be more frequently right-sided, however, no consensus has been reached regarding the location of SRCC, with some reporting the right colon is most commonly affected $(6,18,19)$, others reporting the left colon $(9,15,20)$, and others stating that there is no difference $(3,7,14,21)$.

Macroscopic/microscopic tissue type. Macroscopically, the infiltrating type is most common in colorectal SRCC $(6,9$, 11 ) and type 4 is significantly more common than in typical CRC (8). Microscopically, SRCC is characterized by producing encapsulated mucus in the cytoplasm (Figure 1). Similarly to SRCC, there are also mucinous carcinomas that produce mucus extracellularly. Adenocarcinoma, mucinous carcinoma, and SRCC can coexist simultaneously. For the mixed tissue types, a World Health Organization classification which assesses the proportion taken up in the entire tumor (22), and an assessment method that uses $50 \%$ as a standard (23) have been proposed. In Japan, based on rules governing the treatment of CRC, the tissue type with the greatest area in a specimen usually forms the diagnosis (7).

Tumor depth, invasion, metastasis and recurrence. The histological depth of invasion is reported to be T3 or greater in most cases $(6,18)$, and there are few reports of mucosal or submucosal cancers among those with early-stage SRCC. Nakatani et al. reported 26 cases of early-stage SRCC from Japan (24). Moreover, Hyngstrom et al. found that only an extremely low proportion $(6 \%)$ of SRCCs are stage I at the time of the initial diagnosis (12).
Lymph node metastasis has been found to be more common in SRCC than in adenocarcinoma $(9,18)$ but other studies have found no difference (7). Moreover, both vascular and lymphatic invasion are said to be severe $(6,9$, 14). Yet despite a high degree of vascular invasion, many studies did not find significant differences in liver or lung metastasis in SRCC compared with adenocarcinoma $(6,7,9$, 11). However, to our knowledge, there have not been any reports of detailed investigations into the reasons for this.

While metastasis of adenocarcinoma is said to occur primarily in the liver (25), several studies have indicated that peritoneal dissemination is a type of metastasis that is particularly common in $\operatorname{SRCC}(6,7,9,25)$. Both local and distal recurrences have been reported to be significantly more frequent than for differentiated adenocarcinoma (18). There have also been a few reports of disseminated carcinomatosis of the bone marrow as a distinct form of metastasis $(8,26)$.

Prognosis. SRCC is said to have a 5-year survival rate of 0$12 \%$ and a higher recurrence rate than differentiated adenocarcinoma (SRCC=77\%, adenocarcinoma=38\%) (18); SRCC was also cited as an independent prognostic factor for $\mathrm{CRC}$ in a multivariate analysis. Kakar et al. reported that stage and $B R A F$ mutation in microsatellite-stable (MSS) tumor cases were factors that affected the prognosis of SRCC (27). Inamura et al. found that having even a small number of signet-ring cell components was associated with poor prognosis (28).

\section{Molecular Biological Characteristics}

A variety of genetic analyses of RAS genes and others have been performed for CRC, and have been used to develop molecular-target drugs and chemotherapies. The prognosis of SRCC is clearly worse than that of other tissue types. 

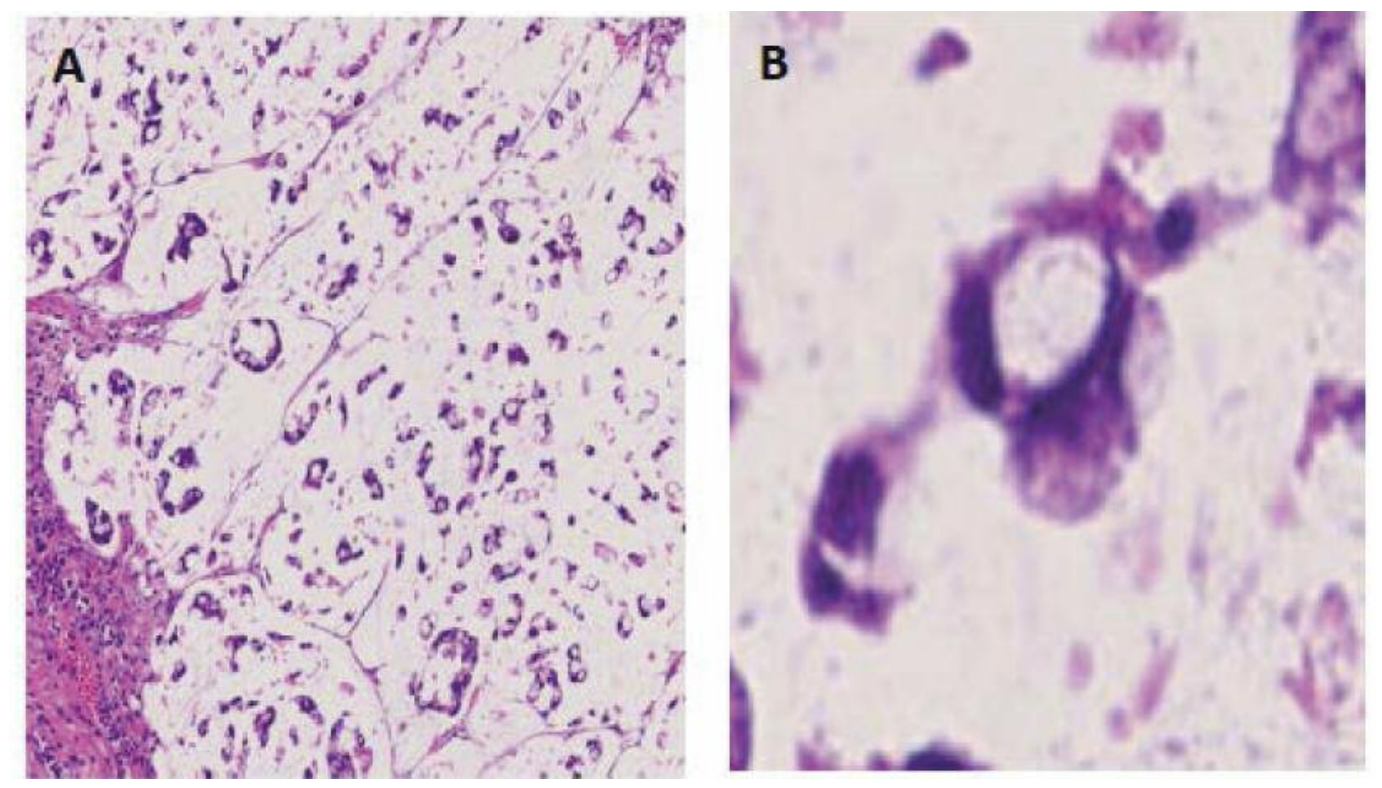

Figure 1. Representative images of colorectal signet ring cell adenocarcinoma at low magnification $(\times 10)(A)$ and high magnification $(\times 40)(B)$. Tumor cells have lost contact with each other and the form of the cells is quite singular 'signet ring' shape containing mucin in its cytoplasm.

However, due to the infrequency of colorectal SRCC, there has been little research analyzing its genetic background. Below, we discuss the reports that have addressed genetic analysis of SRCC.

$R A S / R A F$ mutations. Activation of the receptor tyrosine kinase pathway, mainly with respect to RAS, is often discussed regarding CRC. Moreover, RAS gene mutations have been cited as factors that result in CRC resistance to therapy or it becoming malignant $(29,30)$. Kakar et al. and Ogino et al. both reported finding no difference in KRAS mutations between SRCC and non-mucin-producing tumors such as differentiated adenocarcinoma $(27,31)$. However, $B R A F$ mutations are said to be common in SRCC, with Ogino et al. reporting BRAF mutations at rates of $22-33 \%$ in a group containing SRCC components, compared to $15-27 \%$ in a group containing mucinous carcinomas and $8.6 \%$ in a group containing neither SRCC nor mucinous components (31).

Phosphoinositide 3-kinase (PI3K) pathway. In cellular experiments, Kobayashi et al. reported that inserting genes related to the PI3K pathway into a well-differentiated adenocarcinoma cell line changed it into a mucin-producing phenotype resembling SRCC. When these cells were transplanted into nude mice, they displayed properties of an infiltrative cancer resembling SRCC (32). Using the same cells, they reported that when avian erythroblastosis oncogene B2 (ERBB2) and -3 were bound to mucin 4
(MUC4), which is contained in mucin, it caused phosphorylation of ERBB3, a decrease in intracellular adhesion, and dedifferentiation, which they suggested could be related to the morphological characteristics and malignancy of SRCC (33). Clinically, activation of the PI3K pathway has not been reported in any SRCC cases as far as we are aware.

Intracellular adhesion molecules and tumor type. Terada. conducted immunostaining with epithelial membrane antigens (EMA) on cases of colorectal SRCC, and the results suggested down-regulation of EMA in colorectal SRCC (34). Furthermore, Cabibi et al. reported strong expression of matrix metalloproteinase-1 and low expression of Ecadherin, beta-catenin, and fibronectin in colorectal SRCC (20). As described above, the binding of ERBB2/3 to mucin is thought to cause a decrease in intracellular adhesion molecules.

One form of genetic expression that is characteristic of SRCC is low E-cadherin expression and strong matrix metalloproteinase (MMP) expression (20). A decline in expression of cellular adhesion molecules and an enhancement of extracellular matrix degradation enzymes are thought to be the reason for the lack of cell mass formation and tumor tendency to be flat or infiltrative type. For distant metastasis to occur, tumorigenicity must be maintained and a tumor mass needs to form. However, reduced cellular adhesion makes forming a tumor mass at the metastatic 
lesion difficult, which is thought to be the reason behind the formation of only disseminated lesions.

Chromosomal instability (CIN), MSI and CIMP. CIN is a gross genetic mutation that occurs at the chromosomal level. CINpositive CRC or typical CRC include MSS, CIMP-negative, $K R A S$, and $B R A F$ wild-type tumors. The genetic background of SRCC, as mentioned previously, is MSI-high, CIMP-high and harboring $K R A S / B R A F$ mutation hence it is possible to say it is the mirror image of typical CRC. MSI is a mutation that occurs during the replication of base pairs (35). Ogino et al. reported significantly more MSI-positive cases among SRCC cases (31). BRAF mutations are often seen in MSI-high cases (36), which is consistent with the previous report that found frequent BRAF mutations in SRCC. CIMP is a phenotype in which genetic expression is suppressed by methylation of gene promoters (37). CIMP-positive CRCs are reported to have high rates of $K R A S$ and $B R A F$ mutations (38, 39). Furthermore, CIMP-positive CRC is often accompanied by methylation of the mismatch repair gene human MutL homolog 1 (MLH1), which leads to MSI-high CRC (40). Kakar et al. reported that CIMP positivity is more common in SRCC than in differentiated adenocarcinoma (27). Imamura et al. examined tissue types with and without SRCC and found more CIMP-positive cases among those with SRCC components (28), suggesting a deep relationship between methylation and SRCC.

Young age of colorectal SRCC and MSI/CIMP. There has been little detailed research into the young age of onset of colorectal SRCC. Lynch syndrome is a typical form of earlyonset CRC which has been shown to be caused by dysfunctions due to mutations of mismatch repair genes MLH1, human MutS homolog (MSH2) 2, MLH1, MSH6, PMS1 homolog 1 (PMS1) and PMS2 (41). MSI-high and CIMP-high status have been found in the genetic background of colorectal SRCC. Therefore, MSI or methylation may suppress expression of these mismatch repair genes to cause young onset of multiple malignancies. Leggett et al. hypothesized that $B R A F$ mutations in healthy mucosa lead to MLH1 methylation, MSI, and CIMP-high status (42). This characteristic is often seen in SRCC hence it could be related to early onset of the disease.

Loss of heterozygosity $(\mathrm{LOH})$. $\mathrm{LOH}$ is when one member of a pair of alleles of a gene is missing. Genes with $\mathrm{LOH}$ tend to lose their functions. $\mathrm{LOH}$ isclosely related to CIN, with LOH appearing frequently in CIN-high cases (43). 18qLOH has been reported to be a prognostic factor for $\mathrm{CRC}$ and has been a focus of attention (44). Kakar et al. reported LOH positivity at a higher rate in SRCC than in differentiated adenocarcinoma; however, they also reported that this did not affect prognosis (27).
Microribonucleic acid (microRNA) and non-coding RNA mutations. A few studies have examined microRNA in gastric SRCC $(45,46)$, but to our knowledge none have examined microRNA in colorectal SRCC. Li et al. compared microRNA expression between gastric SRCC and gastric adenocarcinoma, finding up-regulation of $m i R-181 b, m i R-29 c$, $m i R-381$, and others in gastric SRCC (46). There have been only a few reports on these microRNA families in CRC, therefore further investigations are needed in colorectal SRCC.

Regarding LINE1 methylation, Ogino et al. reported that LINE1 hypomethylation in CRC is associated with worse prognosis than hypermethylation (47). Thus, it is possible that this is not a determining factor for malignancy in colorectal SRCC.

Pathological diagnosis and biomolecular alteration. At present, pathological diagnoses are made based on the proportion SRCC takes up in a lesion. While commonalities have been observed with mucinous adenocarcinoma, such as mucin production, cases with SRCC components exhibit clearly poorer prognoses and its genetic expression pattern appears to differ greatly from regular CRC types. Therefore, diagnosis of SRCC in the future should be based not only on morphology, but also on a comprehensive genetic analysis that covers alterations of CIN, MSI, CIMP, MMP expression, E-cadherin, and BRAF mutations.

\section{Treatment of SRCC and Proposal of Future Therapy According to the Genetic Background of SRCC}

The prognosis of colorectal SRCC is extremely poor. Improving it requires both intensive care and therapies that take its genetic background into consideration. Current therapy and undergoing treatment trials are discussed below.

Current therapy. Similar to other tissue types, the standard treatment for SRCC is surgical therapy when possible. However, as reported by Inamura et al., the prognosis of SRCC is clearly poorer than that of adenocarcinoma (28). With resectable metastatic lesions, the prognosis of patients who undergo surgery is reported to be 27 months in those with metastasis of adenocarcinoma and only 17 months with metastasis of SRCC (48).

The high recurrence rate means patients must be carefully managed after surgery. In patients with stage III SRCC, postoperative adjuvant therapy has been found to have some effect, although poorer than in patients with adenocarcinoma (25). Furthermore, good effects from preoperative chemotherapy have been reported in cases of rectal cancer that are histologically SRCC (49).

Systemic chemotherapy, surgery, and hyperthermic intraperitoneal chemotherapy have been reported to have 
some effect on peritoneal dissemination of CRC, with an improvement of overall survival of a maximum of 12 months being shown for patients with sporadic peritoneal dissemination $(50,51)$. However, while overall survival of 35.1 months was reported for those treated with surgery plus hyperthermic intraperitoneal chemotherapy for other tissue types, the outlook for those with peritoneal dissemination of SRCC was significantly worse, with a median overall survival of 14.1 months. The recurrence rate for SRCC was also higher at $68.8 \%$ compared with $43.7 \%$ for other tissue types (29). These findings indicate that treatments for dissemination need further investigation.

Future therapeutic proposals. Ogino et al. reported BRAF mutations in $22-33 \%$ of a group with tumors containing SRCC components, which was significantly higher than in a group without SRCC components (52). CRC with BRAF mutation has been treated with a combination of BRAF and mitogen-activated kinase kinase enzymes (MEK) inhibitors, but response rates have been low at $4-12 \%(53,54)$. Feedback of BRAF inhibition increases epidermal growth factor receptor (EGFR) activation, which has been shown to sustain proliferation of cancer cells (55). Therefore, these poor effects are thought to be due to an increase of EGFR expression under $B R A F$ mutation. Corcoran et al. reported that a combination of anti-EGFR and BRAFenzyme inhibitor vemurafenib had a strong synergistic effect on persistent mitogen-activated protein kinase pathway suppression in cancer cells (56). Clinical trials using a BRAF inhibitor with anti-EGFR and a BRAF inhibitor with anti-EGFR plus a $\mathrm{PI} 3 \mathrm{~K}$ inhibitor or a MEK inhibitor are in progress (ClinicalTrials.gov Identifier: NCT01750918). It is hoped these therapies will be effective in colorectal SRCC, which exhibits $B R A F$ mutations relatively frequently.

Millis et al. found PI3K mutations in $17 \%$ of CRC cases (57) and a clinical trial on a PI3K inhibitor is being conducted (58). They demonstrated the involvement of PI3K in SRCC in cellular experiments, making it a focus of attention as a therapeutic target for SRCC.

The recent introduction of immune checkpoint inhibitors into clinical practice has produced extremely good results in MSI-high CRC (59). Due to the high prevalence of MSI-high cases in SRCC, use of immune checkpoint inhibitors should also be considered.

\section{Conclusion}

Colorectal SRCC has quite significantly different clinicopathological features and genetic background compared with typical CRC. In order to make a suitable diagnosis and propose a precise therapeutic strategy, it is necessary to fully understand the clinical, biological characteristics and genetic backdrop of colorectal SRCC.

\section{References}

1 Siegel R, Ma J, Zou Z and Jemal A: Cancer statistics, 2014. CA: Cancer J Clin 64: 9-29, 2014.

2 Katanoda K, Hori M, Matsuda T, Shibata A, Nishino Y, Hattori M, Soda M, Ioka A, Sobue T and Nishimoto H: An updated report on the trends in cancer incidence and mortality in Japan, 1958-2013. Jpn J Clin Oncol 45: 390-401, 2015.

3 Nissan A, Guillem JG, Paty PB, Wong WD and Cohen AM: Signet-ring cell carcinoma of the colon and rectum: a matched control study. Dis Colon Rectum 42: 1176-1180, 1999.

4 Otsuji E, Yamaguchi T, Sawai K and Takahashi T: Characterization of signet ring cell carcinoma of the stomach. $\mathrm{J}$ Surg Oncol 67: 216-220, 1998

5 Nitsche U, Friess H, Agha A, Angele M, Eckel R, Heitland W, Jauch K-W, Krenz D, Nüssler NC, Rau H-G, Ruppert R, Schubert-Fritschle G, Wilhelm D, Werner $J$ and Engel J: Prognosis of mucinous and signet-ring cell colorectal cancer in a population-based cohort. J Cancer Res Clin Oncol 142: 23572366, 2016.

6 Haraguchi Y, Nagahama A, Tomiki Y, Okamura S,Takegawa S and Sakakibara N: Clinicopathologic features of signet-ring cell carcinoma of the colon and rectum. J Jpn Surg Assoc 56: 1811$1815,1995$.

7 Goto J, Kita K, Fujiyoshi M, Hirokata G, Imai K, Kawai T, Yanagida N, Akabane $\mathrm{H}$, Nakano $\mathrm{S}$ and Takahashi $\mathrm{M}$ : Clinicopathologic features of signet-ring cell carcinoma of the colon and rectum. J Jpn Surg Assoc 66: 2915-2920, 2005.

8 Nishimura Y, Sekime T, Kobayashi T, Amikura K, Sakamoto H and Tanaka Y: Clinicopathological study of rare histological types of colorectal cancer-multi-institutional questionnaire study. Nippon Daicho Komonbyo Gakkai Zasshi 57: 132-140, 2004.

9 Makino T, Mishima H, Ikenaga M, Tsujinaka T, Takeda M and Mano M: Clinicopathologic features of signet-ring cell carcinoma of the colon and rectum. Jpn J Gastroenterol Surg 39: 16-22, 2006.

10 Taghavi S, Jayarajan SN, Davey A and Willis AI: Prognostic significance of signet ring gastric cancer. J Clin Oncol Off J Am Soc Clin Oncol 30: 3493-3498, 2012.

11 Izumi Y, Kawasaki T, Maruyama S, Sato E, Aoi T, Nosaka T, Ueda Y, Okabe S, Endou M, Okamoto K, Sugihara K, Nakagima A, Sato Y and Kikuchii M: Clinicopathological features of poorly differentiated carcinoma of the large intestine. J Jpn Surg Assoc 55: 1385-1391, 1994.

12 Hyngstrom JR, Hu C-Y, Xing Y, You YN, Feig BW, Skibber JM, Rodriguez-Bigas MA, Cormier JN and Chang GJ: Clinicopathology and outcomes for mucinous and signet ring colorectal adenocarcinoma: analysis from the National Cancer Data Base. Ann Surg Oncol 19: 2814-2821, 2012.

13 Mizushima T, Nomura M, Fujii M, Akamatsu H, Mizuno H, Tominaga H, Hasegawa J, Nakajima K, Yasumasa K, Yoshikawa $\mathrm{M}$ and Nishida T: Primary colorectal signet-ring cell carcinoma: clinicopathological features and postoperative survival. Surg Today 40: 234-238, 2010.

14 Tung SY, Wu CS and Chen PC: Primary signet ring cell carcinoma of colorectum: an age- and sex-matched controlled study. Am J Gastroenterol 91: 2195-2199, 1996.

15 Giacchero A, Aste H, Baracchini P, Conio M, Fulcheri E, Lapertosa $G$ and Tanzi R: Primary signet-ring carcinoma of the large bowel. Report of nine cases. Cancer 56: 2723-2726, 1985. 
16 Kawasaki C, Kushima R, Hattori T, Hirano M, Yamamoto A, Fujimura M and Mori A: A study of biological characteristics of signet-ring cell carcinomas of the colon. Nippon Daicho Komonbyo Gakkai Zasshi 47: 476-484, 1994.

17 Lee MS, Menter DG and Kopetz S: Right versus left colon cancer biology: integrating the consensus molecular subtypes. JNCCN 15: 411-419, 2017.

18 Nitsche U, Zimmermann A, Späth C, Müller T, Maak M, Schuster T, Slotta-Huspenina J, Käser SA, Michalski CW, Janssen K-P, Friess H, Rosenberg R and Bader FG: Mucinous and signet-ring cell colorectal cancers differ from classical adenocarcinomas in tumor biology and prognosis. Ann Surg 258: 775-782, 2013.

19 Connelly JH, Robey-Cafferty SS, el-Naggar AK and Cleary KR: Exophytic signet-ring cell carcinoma of the colorectum. Arch Pathol Lab Med 115: 134-136, 1991.

20 Cabibi D, Calascibetta A, Aragona F, Martorana A, Campione M and Sanguedolce R: Differing expression of metalloprotease and of adhesion molecules in signet-ring cell and intestinal colorectal carcinoma. Anticancer Res 29: 4417-4422, 2009.

21 Anthony T, George R, Rodriguez-Bigas M and Petrelli NJ: Primary signet-ring cell carcinoma of the colon and rectum. Ann Surg Oncol 3: 344-348, 1996.

22 Hamilton SR and Aaltonen LA: Pathology and Genetics of Tumours of the Digestive System. IARC press Lyon, 2000.

23 Washington MK, Berlin J, Branton P, Burgart LJ, Carter DK, Fitzgibbons PL, Halling K, Frankel W, Jessup J, Kakar S, Minsky B, Nakhleh R, Compton CC and Members of the Cancer Committee and College of American Pathologists: Protocol for the examination of specimens from patients with primary carcinoma of the colon and rectum. Arch Pathol Lab Med 133: 1539-1551, 2009.

24 Nakatani S, Waki N, Yamashita K, Nagasaka T, Mori T and Fujiwara T: Early colonic cancer with signet-ring cell carcinoma, mucinous and poorly differentiated adenocarcinoma of the anal canal-a case report. Nippon Daicho Komonbyo Gakkai Zasshi 68: 239-245, 2015

25 Hugen N, van de Velde CJH, de Wilt JHW and Nagtegaal ID: Metastatic pattern in colorectal cancer is strongly influenced by histological subtype. Ann Oncol 25: 651-657, 2014.

26 Nagahisa Y, Kai C, Hattori K, Sakurai R, Matsuba Y, Hashida $\mathrm{K}$, Kawamoto $\mathrm{K}$ and Itou T: A case of signet-ring cell carcinoma of the sigmoid colon with disseminated carcinomatosis successfully treated with CPT-11/Panitumumab. Cancer Chemotherapy 42: 2477-2479, 2015.

27 Kakar S, Deng G, Smyrk TC, Cun L, Sahai V and Kim YS: Loss of heterozygosity, aberrant methylation, BRAF mutation and KRAS mutation in colorectal signet ring cell carcinoma. Mod Pathol 25: 1040-1047, 2012.

28 Inamura K, Yamauchi M, Nishihara R, Kim SA, Mima K, Sukawa Y, Li T, Yasunari M, Zhang X, Wu K, Meyerhardt JA, Fuchs CS, Harris CC, Qian ZR and Ogino S: Prognostic significance and molecular features of signet-ring cell and mucinous components in colorectal carcinoma. Ann Surg Oncol 22: 1226-1235, 2015.

29 Van Cutsem E, Kohne C.H, Hitre E, Zaluski J, Chang Chien CR, Makhson A, D’Haens G, Pinter T, Lim R, Bodoky G, Roh JK, Folprecht G, Ruff P, Stroh C, Tejpar S, Schlichting M, Nippgen $\mathrm{J}$ and Rougier P: Cetuximab and chemotherapy as initial treatment for metastatic colorectal cancer. N Engl J Med 360: 1408-1417, 2009.
30 Bokemeyer C, Köhne C-H, Ciardiello F, Lenz H-J, Heinemann V, Klinkhardt U, Beier F, Duecker K, van Krieken JH and Tejpar S: FOLFOX4 plus cetuximab treatment and RAS mutations in colorectal cancer. Eur J Cancer 51: 1243-1252, 2015.

31 Ogino S, Brahmandam M, Cantor M, Namgyal C, Kawasaki T, Kirkner G, Meyerhardt JA, Loda M and Fuchs CS: Distinct molecular features of colorectal carcinoma with signet ring cell component and colorectal carcinoma with mucinous component. Mod Pathol Off J United States Can Acad Pathol Inc 19: 59-68, 2006.

32 Kobayashi M, Nagata S, Iwasaki T, Yanagihara K, Saitoh I, Karouji Y, Ihara $S$ and Fukui Y: Dedifferentiation of adenocarcinomas by activation of phosphatidylinositol 3-kinase. Proc Natl Acad Sci United States Am 96: 4874-4879, 1999.

33 Kobayashi M, Iwamatsu A, Shinohara-Kanda A, Ihara S and Fukui Y: Activation of ErbB3-PI3-kinase pathway is correlated with malignant phenotypes of adenocarcinomas. Oncogene 22: 1294-1301, 2003.

34 Terada T: An immunohistochemical study of primary signet-ring cell carcinoma of the stomach and colorectum: I. Cytokeratin profile in 42 cases. Int J Clin Exp Pathol 6: 703-710, 2013.

35 Lengauer C, Kinzler KW and Vogelstein B: Genetic instability in colorectal cancers. Nature 386: 623-627, 1997.

36 Timmermann B, Kerick M, Roehr C, Fischer A, Isau M, Boerno ST, Wunderlich A, Barmeyer C, Seemann P, Koenig J, Lappe M, Kuss AW, Garshasbi M, Bertram L, Trappe K, Werber M, Herrmann BG, Zatloukal K, Lehrach $\mathrm{H}$ and Schweiger MR: Somatic mutation profiles of MSI and MSS colorectal cancer identified by whole exome next generation sequencing and bioinformatics analysis. PloS One 5: e15661, 2010.

37 Nosho K, Irahara N, Shima K, Kure S, Kirkner JG, Schernhammer SE, Hazra A, Hunter JD, Quackenbush J, Spiegelman D, Giovannucci LE, Fuchs SC and Ogino S: Comprehensive biostatistical analysis of $\mathrm{CpG}$ island methylator phenotype in colorectal cancer using a large population-based sample. PloS One 3: e3698, 2008.

38 Issa J-P: CpG island methylator phenotype in cancer. Nat Rev Cancer 4: 988-993, 2004.

39 Toyota M, Ohe-Toyota M, Ahuja N and Issa JP: Distinct genetic profiles in colorectal tumors with or without the $\mathrm{CpG}$ island methylator phenotype. Proc Natl Acad Sci United States Am 97: 710-715, 2000.

40 Nagasaka T, Sasamoto H, Notohara K, Cullings HM, Takeda M, Kimura K, Kambara T, MacPhee DG, Young J, Leggett BA, Jass JR, Tanaka N and Matsubara N: Colorectal cancer with mutation in BRAF, KRAS, and wild-type with respect to both oncogenes showing different patterns of DNA methylation. J Clin Oncol Off J Am Soc Clin Oncol 22: 4584-4594, 2004.

41 Van Cutsem E, Kohne CH, Hitre E, Zaluski J, Chang Chien CR, Makhson A, D'Haens G, Pinter T, Lim R, Bodoky G, Roh JK, Folprecht G, Ruff P, Stroh C, Tejpar S, Schlichting M, Nippgen J, and Rougier P: Cetuximab and chemotherapy as initial treatment for metastatic colorectal cancer. N Engl J Med 360: 1408-1417, 2009.

42 Leggett B and Whitehall V: Role of the serrated pathway in colorectal cancer pathogenesis. Gastroenterology 138: 20882100, 2010.

43Pino MS and Chung DC: The chromosomal instability pathway in colon cancer. Gastroenterology 138: 2059-2072, 2010. 
44 Popat S and Houlston RS: A systematic review and metaanalysis of the relationship between chromosome 18q genotype, DCC status and colorectal cancer prognosis. Eur J Cancer 41: 2060-2070, 2005.

45 Chen J, Sun D, Chu H, Gong Z, Zhang C, Gong B, Li Y, Li N and Jiang L: Screening of differential microRNA expression in gastric signet ring cell carcinoma and gastric adenocarcinoma and target gene prediction. Oncol Rep 33: 2963-2971, 2015.

$46 \mathrm{Li}$ FQ, Xu B, Wu YJ, Yang ZL and Qian JJ: Differential microRNA expression in signet-ring cell carcinoma compared with tubular adenocarcinoma of human gastric cancer. Genet Mol Res 14: 739-747, 2015.

47 Ogino S, Nosho K, Kirkner GJ, Kawasaki T, Chan AT, Schernhammer ES, Giovannucci EL and Fuchs CS: A cohort study of tumoral LINE-1 hypomethylation and prognosis in colon cancer. J Natl Cancer Inst 100: 1734-1738, 2008.

48 Fu J, Wu L, Jiang M, Tan Y, Li D, Chen F, Jiang T and Du J: Signet ring cell carcinoma of resectable metastatic colorectal cancer has rare surgical value. J Surg Oncol 114: 1004-1008, 2016.

49 Jayanand SB, Seshadri RA and Tapkire R: Signet ring cell histology and non-circumferential tumors predict pathological complete response following neoadjuvant chemoradiation in rectal cancers. Int J Colorectal Dis 26: 23-27, 2011.

50 Washington MK, Berlin J, Branton PA, Burgart LJ, Carter DK, Fitzgibbons PL, Frankel WL, Jessup JM, Kakar S, Minsky B, Nakhleh RE, Compton CC and Cancer Committee and College of American Pathologists: Protocol for the examination of specimens from patients with primary carcinomas of the colon and rectum. Arch Pathol \& Lab Med 132: 1182-1193, 2008.

51 Bloemendaal ALA, Verwaal VJ, van Ruth S, Boot $\mathrm{H}$ and Zoetmulder FAN: Conventional surgery and systemic chemotherapy for peritoneal carcinomatosis of colorectal origin: a prospective study. Eur J Surg Oncol 31: 1145-1151, 2005.

52 Ogino S, Brahmandam M, Cantor M, Namgyal C, Kawasaki T, Kirkner G, Meyerhardt JA, Loda M and Fuchs CS: Distinct molecular features of colorectal carcinoma with signet ring cell component and colorectal carcinoma with mucinous component. Mod Pathol 19: 59-68, 2005.

53 Kopetz S, Desai J, Chan E, Hecht JR, O'Dwyer PJ, Maru D, Morris V, Janku F, Dasari A, Chung W, Issa J-PJ, Gibbs P, James B, Powis G, Nolop KB, Bhattacharya S and Saltz L: Phase II pilot study of vemurafenib in patients with metastatic BRAFmutated colorectal cancer. J Clin Oncol 33: 4032-4038, 2015.
54 Corcoran RB, Atreya CE, Falchook GS, Kwak EL, Ryan DP, Bendell JC, Hamid O, Messersmith WA, Daud A, Kurzrock R, Pierobon M, Sun P, Cunningham E, Little S, Orford K, Motwani M, Bai Y, Patel K, Venook AP and Kopetz S: Combined BRAF and MEK inhibition with dabrafenib and trametinib in BRAF V600-mutant colorectal cancer. J Clin Oncol 33: 4023-4031, 2015.

55 Prahallad A, Sun C, Huang S, Di Nicolantonio F, Salazar R, Zecchin D, Beijersbergen RL, Bardelli A and Bernards R: Unresponsiveness of colon cancer to BRAF(V600E) inhibition through feedback activation of EGFR. Nature 483: 100-103, 2012.

56 Corcoran RB, Ebi H, Turke AB, Coffee EM, Nishino M, Cogdill AP, Brown RD, Della Pelle P, Dias-Santagata D, Hung KE, Flaherty KT, Piris A, Wargo JA, Settleman J, Mino-Kenudson $\mathrm{M}$ and Engelman JA: EGFR-mediated re-activation of MAPK signaling contributes to insensitivity of BRAF-mutant colorectal cancers to RAF inhibition with vemurafenib. Cancer Discov 2: 227-235, 2012.

57 Millis SZ, Ikeda S, Reddy S, Gatalica Z and Kurzrock R: Landscape of phosphatidylinositol-3-kinase pathway alterations across 19784 diverse solid tumors. JAMA Oncol 2: 1565-1573, 2016.

58 Ganesan P, Janku F, Naing A, Hong DS, Tsimberidou AM, Falchook GS, Wheler JJ, Piha-Paul SA, Fu S, Stepanek VM, Lee JJ, Luthra R, Overman MJ, Kopetz ES, Wolff RA and Kurzrock $\mathrm{R}$ : Target-based therapeutic matching in early-phase clinical trials in patients with advanced colorectal cancer and PIK3CA mutations. Mol Cancer Ther 12: 2857-2863, 2013.

59 Le DT, Uram JN, Wang H, Bartlett BR, Kemberling H, Eyring AD, Skora AD, Luber BS, Azad NS, Laheru D, Biedrzycki B, Donehower RC, Zaheer A, Fisher GA, Crocenzi TS, Lee JJ, Duffy SM, Goldberg RM, de la Chapelle A, Koshiji M, Bhaijee F, Huebner T, Hruban RH, Wood LD, Cuka N, Pardoll DM, Papadopoulos N, Kinzler KW, Zhou S, Cornish TC, Taube JM, Anders RA, Eshleman JR, Vogelstein B and Diaz LA: PD-1 blockade in tumors with mismatch-repair deficiency. New Engl J Med 372: 2509-2520, 2015.

Received May 2, 2017

Revised May 30, 2017

Accepted June 20, 2017 